\title{
Continuous Improvements of a Clinical Pathway Increased Its Feasibility and Improved Care Providers' Perception in TKA
}

\author{
Tae Kyun Kim, $\mathrm{MD}^{1}$, Moon Jong Chang, $\mathrm{MD}^{2}$, Seok Jin Kim, $\mathrm{MD}^{3}$, Young Dong Song, $\mathrm{MD}^{1}$, and \\ Sei Kyoung Kim, $\mathrm{RN}^{1}$ \\ ${ }^{1}$ Department of Orthopaedic Surgery, Seoul National University Bundang Hospital, Seongnam; ${ }^{2}$ Department of Orthopaedic Surgery, Samsung Medical Center, Seoul; \\ ${ }^{3}$ Department of Orthopaedic Surgery, Sinwoo Hospital, Seongnam, Korea
}

Purpose: We aimed to determine 1) whether dropout rate decreased and 2) whether health care providers' perceptions were changed with continued improvements of contents of clinical pathway (CP) for total knee arthroplasty (TKA).

Materials and Methods: This retrospective study included two separate analyses of patients and health care providers. In the analysis of patients, dropout rates and reasons were evaluated in two cohorts of patients who underwent TKA with CP applied at two different time periods (384 patients from 2009 to 2010 and 242 patients from 2012 to 2013). Contents of CP were continuously improved during the 3-year interval. Self-administered questionnaire surveys targeted to health care providers were carried out twice (2010 and 2013) and compared.

Results: Dropout rate decreased from $19.1 \%$ in the first time period to $10.4 \%$ in the second time period. Although overall satisfaction of care providers was high at both time-points, doctors had more favorable perceptions than nurses; most positive changes of perception were noted in nurses. The health care providers' perceptions for potential concerns of $\mathrm{CP}$ were improved while the perceptions for potential benefits and satisfaction were maintained.

Conclusions: Continuously improved CP has increased feasibility for TKA patients and reduced health care providers' concern about its value. We propose that $\mathrm{CP}$ can be implemented and actively used to improve the outcomes and efficacy of patient care for TKA, regardless of the rotation of care providers.

Keywords: Knee, Arthroplasty, Clinical pathways, Health care providers

\section{Introduction}

A clinical pathway $(\mathrm{CP})$ is a structured care plan that indicates the sequence and timing of care actions necessary to achieve goals with optimal efficiency ${ }^{1-3)}$. CPs have been found to be ef-

Received August 29, 2014; Revised October 4, 2014;

Accepted October 27, 2014

Correspondence to: Tae Kyun Kim, MD

Department of Orthopaedic Surgery, Seoul National University Bundang Hospital, 82 Gumi-ro 173beon-gil, Bundang-gu, Seongnam 463-707, Korea

Tel: +82-31-787-7196, Fax: +82-31-787-4056

E-mail: osktk@snubh.org

This is an Open Access article distributed under the terms of the Creative Commons Attribution Non-Commercial License (http://creativecommons.org/licenses/by-nc/3.0/) which permits unrestricted non-commercial use, distribution, and reproduction in any medium, provided the original work is properly cited. ficient and have advantages for high volume procedures that lack substantial unexpected events ${ }^{4,5}$. It was previously revealed that implementation of a $\mathrm{CP}$ could reduce hospital stay, cost and complication rate when applied to relevant indications in various fields of medicine ${ }^{1,-25)}$. For patients undergoing total knee arthroplasty (TKA), an increase in functional outcome and a decrease in pain after implementing the $\mathrm{CP}$ were reported ${ }^{6,25)}$.

However, there are also concerns about CPs. CPs inherently have limited flexibility for patients' individual conditions. Thus, a $\mathrm{CP}$ may not be an optimal approach for a patient and/or disease with great variability during treatment. Under such circumstances, frequent unexpected events during the treatment may lead to the frequent changes of the care plan or dropouts from the CP. These dropouts can negatively affect patient outcomes and the efficiency of patient care. Because TKA is primarily performed in elderly patients with frequent comorbidities, a concern about unexpected events related to these comorbidities has led to the 
question of whether TKA is an ideal procedure for the application of a CP.

Nonetheless, it is possible to establish an advanced CP system that enables us to cope with individual differences among TKA patients and unexpected events that arise during their care, based on various perioperative management methods for TKA patients reported by recent studies and the accumulated experience of health care providers. It is expected that this improved $\mathrm{CP}$ can reduce the dropout rate of TKA patients and improve the health care providers' perception about the CP. If these were accomplished, the CP would become a more optimal, standardized care system for TKA patients by continuous improvement of the contents of the CP for TKA. However, no previous studies have rigorously studied these issues of a CP for TKA.

We, therefore, aimed to determine 1) whether the dropout rate decreased and 2) whether health care providers' perceptions were changed with continued improvements of the contents of our $\mathrm{CP}$ for TKA. We hypothesized that the continued improvements of the CP contents would reduce the dropout rate and improve the health care providers' perceptions about the CP for TKA.

\section{Materials and Methods}

This observational study was performed using medical chart review and self-administered questionnaires, and involved two separate analyses: 1) analysis of the patients who underwent primary TKA and 2) analysis of the health care providers. Each analysis comprised two cohorts from two different time periods. This study was approved by Institutional Review Board of the authors' hospital.

\section{Subjects for Analysis of Dropout Rate from the CP}

Since December 2007, a CP was applied to all the patients undergoing primary TKA in our institute, without exception. Analysis of dropout rate from the CP included 626 patients who underwent primary TKA with application of the CP. The patients comprise two time period groups. The first time period group consisted of 384 patients who underwent primary TKA from April 2009 to March 2010 at our institution. The second time period group included 242 patients who underwent primary TKA from April 2012 through March 2013. The time period groups did not differ in sex distribution; however, they differed in terms of age, height, weight and body mass index (BMI) (Table 1).

\section{Subjects for Analysis of Health Care Providers' Perception}

In total, 98 health care providers were included; they comprised the residents and the nurses who had experiences with both the $\mathrm{CP}$ care and non-CP care in the Department of Orthopedic Surgery at our institution. There were 11 residents and 21 nurses who completed the survey of 2010; 15 residents and 51 nurses completed the survey of 2013.

Between the two periods, we improved the CP in terms of medical and non-medical contents. For preemptive pain management, one hour before surgery, multimodal oral analgesic drugs were administered in addition to celecoxib $200 \mathrm{mg}$ on as-needed basis $^{26)}$. To manage blood loss, the use of tranexamic acid (TNA) was added. In unilateral TKAs, patients were given a $10 \mathrm{mg} / \mathrm{kg}$ of body weight dose of TNA 30 minutes before tourniquet deflation, and the same dose was repeated 3 hours after the commencement of the first injection. In simultaneous bilateral TKAs, the same dose of TNA was administered 30 minutes before tourniquet deflation for the 1st operation, then 30 minutes before tourniquet deflation for the 2 nd operation, and finally, the same dose was repeated 3 hours after the commencement of the second injection $^{27)}$. To prevent postoperative emesis, patients received $10 \mathrm{mg}$ intravenous dexamethasone 1 hour before surgery ${ }^{26)}$. For deep vein thrombosis prophylaxis, postoperative rivaroxaban was added. Patients started rivaroxaban $10 \mathrm{mg}$ on the second day after surgery. For the non-medical contents of the CP, we made convenient icons to add an order in the electron medical record system, made a CP for diabetes mellitus patients, and had regular meetings so that it was easier to operate in terms of selection of the $\mathrm{CP}$, reporting problems about the patients, and communication among health care providers.

Table 1. Patient Demographics of Two Different Time Period Groups

\begin{tabular}{lccr}
\hline \multicolumn{1}{c}{ Parameter } & First time period $(\mathrm{n}=384)$ & Second time period $(\mathrm{n}=242)$ & $\mathrm{p}$-value \\
\hline Age $(\mathrm{yr})$ & $70(6.6)$ & $72(6.2)$ & $<0.001$ \\
Female $(\%)$ & 90 & $152(7.1)$ & 0.501 \\
Height $(\mathrm{cm})$ & $154(7.3)$ & $62(8.9)$ & 0.036 \\
Weight $(\mathrm{kg})$ & $65(10.0)$ & $26.6(3.0)$ & $<0.001$ \\
Body mass index $\left(\mathrm{kg} / \mathrm{m}^{2}\right)$ & $27.4(3.6)$ & 0.007 \\
\hline
\end{tabular}

Data are presented as mean (standard deviation). 
The dropout rate and the reasons for dropout were investigated by reviewing the medical records. The patients were classified as 'completion' of the $\mathrm{CP}$ or 'dropout' from the $\mathrm{CP}$. According to the $\mathrm{CP}$ protocol, all elective patients undergoing primary TKA are admitted the day before surgery, the patients undergoing unilateral primary TKA are discharged 7 days after surgery, the patients undergoing staged bilateral primary TKA are discharged 7 days after the second knee surgery (i.e., 14 days after the first knee surgery), and the patients undergoing simultaneous bilateral primary TKA are discharged 9 days after surgery in our hospital. This schedule for discharge was not changed during study period. The outcome was defined as 'dropout' if the patient failed to complete the CP for any reason, including a prolonged hospital stay of $>2$ days. Otherwise, the outcome was defined as 'completion' of the CP. The reasons for dropout were classified into non-medical reasons and 8 medical reasons. The non-medical reasons included earlier or later discharge attributable to the patients' desire. Medical reasons were classified into the following 8 categories: 1 ) delayed rehabilitation, 2) wound complication, 3) acute postoperative infection, 4) minor systemic problem, 5) major systemic problem, 6) other management problem not related to the knee joint, 7) intraoperative complication, and 8) mortality. Delayed rehabilitation was defined as withdrawal from the $\mathrm{CP}$ because of the problems related to ambulation and/or range of motion of the knee joint. Wound complication was defined as a persistent discharge from the wound during hospitalization. Cardiopulmonary complication was classified as a major systemic problem, while the other systemic complications were classified as a minor systemic problem. If a medical problem unrelated to the operated knee joint, such as voiding difficulty, required management, this reason was classified as other management not related to knee joint. In addition, complications such as neurovascular injury or additional ligament injury that occurred during the operation were classified as intraoperative complication. A death associated with the operation, either directly or indirectly, was classified as mortality.

Health care providers' perceptions about the $\mathrm{CP}$ were evaluated using a self-administered questionnaire that consisted of 16 questions (Appendix). It had the following three sections: 9 questions about potential benefits, 4 questions about potential concerns, and 3 questions about valuation. The question about satisfaction with $\mathrm{CP}$ in the valuation section was evaluated using visual ana$\log$ scale that graded 11 steps from 0 to 10 , and the remaining 15 questions were assessed by the Likert scale (5: strongly agree, 4 : agree, 3: neutral, 2: disagree, 1: strongly disagree).

The same survey was carried out twice, in April 2010 and in April 2013. All responders were blinded to the purpose of this study.

Statistical analyses were conducted using SPSS ver. 20.0 (IBM Corp., Armonk, NY, USA), and p-values of $<0.05$ were considered significant. To compare the dropout rate between the two time-period groups, the proportions of the dropout patients were cross-tabulated across the time-period groups, and statistically significance differences were determine using the chi-square test. To compare the frequencies of the dropout reasons between the two time-period groups, the proportions of each reason were calculated for each time-period group, and analyzed using the chisquare test. To compare the perceptions of health care providers about the CP between two time-period groups, the answers for the questions assessed by the Likert scale were dichotomized into 'agree' and 'disagree' ('agree'; strongly agree, agree and 'disagree'; neutral, disagree, strongly disagree), and the proportions of the responders who were in the agree category were cross-tabulated across the time-period groups, and the proportions were compared using the chi-square test or Fisher-exact test. To compare the residents and nurses regarding perceptions of health care providers about the $\mathrm{CP}$, the answers for the questions assessed by the Likert scale were also dichotomized into 'agree' and 'disagree'; the proportions of the responders who were in the agree category were cross-tabulated across the health care provider groups, and analyzed using the chi-square test or Fisher-exact test. To compare health care providers' satisfaction with the $\mathrm{CP}$ between the two time-periods, the means and standard deviations of the scores were calculated and analyzed using student's t-test.

\section{Results}

Dropout rate decreased from $19.1 \%$ in the first time period to $10.4 \%$ in the second time period ( $\mathrm{p}=0.004$ ). The reduction in overall dropout rate was largely attributable to the reduction in dropouts caused by medical reasons (from $12.8 \%$ to $5.4 \%$, $\mathrm{p}=0.003)$ : decreases in delayed rehabilitation and wound complications were the major reasons (Table 2).

There was no change in overall satisfaction with the CP between the first and second periods; however, residents had a more favorable perception than nurses in both time periods (Table 3). The health care provider's perceptions of the potential concerns about the $\mathrm{CP}$ were improved. In contrast, the perceptions on potential benefits, except for economic perspectives, and the levels of satisfaction with CP were maintained. All significant changes in the perceptions of potential benefits between two time periods were observed in nurses. After continued improvement of the $\mathrm{CP}$ contents, nurses agreed that the $\mathrm{CP}$ facilitates the trans- 
Table 2. Comparison of Reasons for Dropout from the Clinical Pathway between the First and Second Time Period Groups

\begin{tabular}{lccc}
\hline \multicolumn{1}{c}{ Dropout reason } & First time period $(\mathrm{n}=84)$ & Second time period $(\mathrm{n}=242)$ & $\mathrm{p}$-value \\
\hline Non-medical reason & $24(6.3)$ & $12(5.0)$ & $13(5.4)$ \\
Medical reason & $49(12.8)$ & $1(0.4)$ & 0.499 \\
$\quad$ Delayed rehabilitation & $11(2.9)$ & $4(1.7)$ & 0.003 \\
Wound complication & $15(3.9)$ & $0(0.0)$ & 0.029 \\
Acute postoperative infection & $3(0.8)$ & $6(2.5)$ & 0.1108 \\
Minor systemic problem & $7(1.8)$ & $0(0.0)$ & 0.575 \\
Major systemic problem & $2(0.5)$ & $1(0.4)$ & 0.261 \\
Other management problem & $9(2.3)$ & $1(0.4)$ & 0.061 \\
Intraoperative complication & $1(0.3)$ & $0(0.0)$ & 0.741 \\
Mortality & $1(0.3)$ & & 0.427 \\
\hline
\end{tabular}

Data are presented as counts (\%).

Table 3. Comparison of the Overall Satisfaction with the Clinical Pathway between Residents and Nurses according to the Study Period

\begin{tabular}{cccc}
\hline \multirow{2}{*}{ Time of survey } & \multicolumn{2}{c}{ Overall satisfaction } & \multirow{2}{*}{ p-value } \\
\cline { 2 - 3 } & Residents & Nurses & \\
\hline 2010 & 7.7 & 6.2 & 0.040 \\
2013 & 8.2 & 6.5 & $<0.001$ \\
p-value & 0.444 & 0.538 & \\
\hline
\end{tabular}

Data are presented as means of visual analog scale $(0-10)$.

fer of a duty ( $43 \%$ vs. $71 \%, \mathrm{p}=0.027)$. The perceptions of whether the CP can improve quality of care and safety were not changed. The perceptions on potential economic benefits, namely reducing hospital cost and length of stay, were changed negatively (Table 4). Regarding the potential concerns about the $\mathrm{CP}$, the negative perceptions of the $\mathrm{CP}$ were reduced in the second time period: only $18 \%$ of the health care providers responded that the CP inhibited creative thinking as a trainee in the second time period compared to $41 \%$ in the first time period ( $\mathrm{p}=0.017$ ). This reduction was largely due to the reduction in negative perception of the residents (from $55 \%$ to $7 \%, \mathrm{p}=0.021$ ) (Table 5). The perceptions about the CP regarding valuation showed no difference between in 2010 and in 2013. However, $83 \%$ of the health care providers included in this study were willing to use the CP if they were given a choice (Table 6).

\section{Discussion}

The CP is optimal for routine procedures without substantial unexpected events and has some inherent limitation in flexibility to adjust to patient's individual conditions. Therefore, the typical characteristics of TKA patients, i.e., elderly individuals frequently with medical comorbidities, have raised concerns about whether TKA is an ideal procedure for applying a CP. In addition, health care providers may have negative perceptions about the application of a CP to TKA patients. However, continued improvements of the CP contents, which enables coping with individual differences in TKA patients, may reduce dropout rates or health care providers' negative views about the CP. To address these issues, we investigated changes in dropout rates in patients who underwent TKA and health care providers' perceptions between two time-periods over an interval of 3 years during which continued improvements of the CP contents for TKA were made.

There were several limitations that should be noted when interpreting our findings. First, this study was conducted using heterogeneous patient groups. In the analysis of dropout rate from the $\mathrm{CP}$, two cohorts had somewhat different demographics in terms of age and BMI. The characteristics of more aged patients in more recent time-period group corresponded to our national trend of TKA candidates ${ }^{28)}$, consistent with the extremely rapid increase of the elderly in our country. These differences in demographics could have introduced a bias. However, considering that the rate of dropout was reduced in the second time period group despite their older age, we believe that the integrity of our study was not jeopardized by demographic differences. Second, we did not examine the changes in health care providers' perceptions among the same providers that worked during the time periods of the two patient cohorts. Instead, we included the residents and the nurses who were available at the time of the each survey. However, we only included the residents and the nurses who had been trained with the same program under the same environment, and thus, the bias originating from different study cohorts 
Table 4. Changes of Health Care Providers' Perceptions about the Clinical Pathway from 2010 to 2013 (Potential Benefits)

\begin{tabular}{|c|c|c|c|}
\hline Question & $2010(n=32)$ & $2013(\mathrm{n}=66)$ & p-value \\
\hline \multicolumn{4}{|l|}{ Quality and safety } \\
\hline Improved quality of care & $22(69)$ & $43(65)$ & 0.724 \\
\hline Residents & $10(91)$ & $14(93)$ & 1.000 \\
\hline Nurses & $12(57)$ & $29(57)$ & 0.983 \\
\hline Reduced order input & $22(69)$ & $45(68)$ & 0.955 \\
\hline Residents & $11(100)$ & $15(100)$ & N/A \\
\hline Nurses & $11(52)$ & $30(59)$ & 0.616 \\
\hline Reduced error & $18(56)$ & $39(59)$ & 0.789 \\
\hline Residents & $9(82)$ & $11(73)$ & 1.000 \\
\hline Nurses & $9(43)$ & $28(55)$ & 0.353 \\
\hline \multicolumn{4}{|l|}{ Economical perspective } \\
\hline Reduced hospital cost & $25(78)$ & $34(52)$ & 0.012 \\
\hline Residents & $10(91)$ & $11(73)$ & 0.356 \\
\hline Nurses & $15(71)$ & $23(45)$ & 0.042 \\
\hline Reduced length of stay & $28(88)$ & $45(68)$ & 0.040 \\
\hline Residents & $9(82)$ & $14(93)$ & 0.556 \\
\hline Nurses & $19(91)$ & $31(61)$ & 0.013 \\
\hline \multicolumn{4}{|l|}{ Communication } \\
\hline Facilitates transferring a duty & $18(56)$ & $50(76)$ & 0.049 \\
\hline Residents & $9(82)$ & $14(93)$ & 0.556 \\
\hline Nurses & $9(43)$ & $36(71)$ & 0.027 \\
\hline Improved communication with patients & $25(78)$ & $48(73)$ & 0.565 \\
\hline Residents & $7(64)$ & $11(73)$ & 0.683 \\
\hline Nurses & $18(86)$ & $37(73)$ & 0.232 \\
\hline Improved communication among health care providers & $27(84)$ & $47(71)$ & 0.155 \\
\hline Residents & $11(100)$ & $14(93)$ & 1.000 \\
\hline Nurses & $16(76)$ & $33(65)$ & 0.342 \\
\hline \multicolumn{4}{|l|}{ Education } \\
\hline Recognized educational benefits & $29(91)$ & $54(82)$ & 0.256 \\
\hline Residents & $9(82)$ & $15(100)$ & 0.169 \\
\hline Nurses & $20(95)$ & $39(77)$ & 0.060 \\
\hline
\end{tabular}

Data are presented as numbers (\%) of the subjects who replied 'agree'.

N/A: not available.

would be minimal.

Our results support the hypothesis that continued improvements of CP contents would decrease the dropout rate. In the literature related to the CP for TKA, most studies excluded the patients with American Society of Anesthesiologists Physical Status Score 3 and $4^{12)}$, chronic opioid use or chronic pain syndrome $^{29)}$, high comorbidities, severe cardiac/respiratory disease, and severe multiple joint involvement ${ }^{30}$. This restrictive strategy could reduce dropout, but also reduce the application rate of the
CP. In contrast, we applied the $\mathrm{CP}$ to the patients undergoing primary TKA without exception. Even with the 100\% application, the dropout rate was reduced to a reasonable level after continued improvement of CP contents. Moreover, the rate of dropout due to medical reasons markedly decreased in the more recent time-period group (12.8\% in the first time-period group vs. $5.4 \%$ in the second time period group) while the dropouts due to nonmedical reasons were not significantly changed. Thus, we believe that a contemporary $\mathrm{CP}$, when its contents have been continu- 
Table 5. Changes of Health Care Providers' Perceptions of the Clinical Pathway from 2010 to 2013 (Potential Concerns)

\begin{tabular}{lrcc}
\hline \multicolumn{1}{c}{ Question } & $\begin{array}{c}2010 \\
(\mathrm{n}=32)\end{array}$ & $\begin{array}{c}2013 \\
(\mathrm{n}=66)\end{array}$ & p-value \\
\hline Inhibits coping with diverse situations & $19(59)$ & $26(39)$ & 0.063 \\
$\quad$ Residents & $6(55)$ & $7(47)$ & 0.691 \\
$\quad$ Nurses & $13(62)$ & $19(37)$ & 0.056 \\
Inhibits creative thinking as a trainee & $13(41)$ & $12(18)$ & 0.017 \\
$\quad$ Residents & $6(55)$ & $1(7)$ & 0.021 \\
$\quad$ Nurses & $7(33)$ & $11(22)$ & 0.295 \\
Inhibits additional order insertion & $24(75)$ & $28(42)$ & 0.002 \\
$\quad$ Residents & $6(55)$ & $5(33)$ & 0.279 \\
$\quad$ Nurses & $18(86)$ & $23(45)$ & 0.002 \\
Has higher risk of malpractice & $21(66)$ & $22(33)$ & 0.003 \\
$\quad$ Residents & $5(46)$ & $5(33)$ & 0.530 \\
$\quad$ Nurses & $16(76)$ & $17(33)$ & 0.001 \\
\hline
\end{tabular}

Data are presented as numbers (\%) of the subjects who replied 'agree'.

ously improved, would be valuable for systematic perioperative care of TKA patients. Findings of our study affirm the hypothesis that the continued improvements of CP contents would improve the health care providers' perceptions about the CP for TKA. Health care providers' perceptions were substantially improved in the potential concerns category. In contrast, the health care providers' perceptions became worse in economic perspective in terms of the hospital cost and length of hospital stay. These are somewhat discordant with the result of previous studies that revealed that a CP was an effective method to reduce hospital cost and length of stay without compromising quality of patient care and safety ${ }^{8,20,30}$. It can be explained by the fact that we did not change the discharge plans of the $\mathrm{CP}$ during the study period although we changed the contents of the $\mathrm{CP}$ to add new drugs and/or interventions for pain and postoperative emesis control. Thus, health care providers might have thought that the hospital cost was increased because of the additional orders for drugs and interventions.

\section{Conclusions}

This study demonstrates that, with continuing improvements in the contents of the $\mathrm{CP}$, this $\mathrm{CP}$ has increased feasibility for TKA patients and reduced health care providers' concern about its value. Our findings suggest that $\mathrm{CP}$ can be safely implemented and actively used as an optimal perioperative care strategy for patients undergoing TKA, regardless of the rotation of care providers.
Table 6. Changes of Health Care Providers' Perceptions of the Clinical Pathway from 2010 to 2013 (Valuation)

\begin{tabular}{lrll}
\hline \multicolumn{1}{c}{ Question } & $\begin{array}{c}2010 \\
(\mathrm{n}=32)\end{array}$ & $\begin{array}{c}2013 \\
(\mathrm{n}=66)\end{array}$ & $\mathrm{p}$-value \\
\hline Improves general medical process & $25(78)$ & $47(71)$ & 0.467 \\
$\quad$ Residents & $8(73)$ & $15(100)$ & 0.063 \\
$\quad$ Nurses & $17(81)$ & $32(63)$ & 0.132 \\
Willing to use clinical pathway & $24(75)$ & $55(83)$ & 0.328 \\
$\quad$ Residents & $10(91)$ & $15(100)$ & 0.423 \\
$\quad$ Nurses & $14(67)$ & $40(78)$ & 0.295 \\
\hline
\end{tabular}

Data are presented as numbers (\%) of the subjects who replied 'agree' and proportions in parentheses.

\section{Conflict of Interest}

No potential conflict of interest relevant to this article was reported.

\section{References}

1. Coffey RJ, Richards JS, Remmert CS, LeRoy SS, Schoville RR, Baldwin PJ. An introduction to critical paths. Qual Manag Health Care. 2005;14:46-55.

2. Sladek ML, Swenson KK, Ritz LJ, Schroeder LM. A critical pathway for patients undergoing one-day breast cancer surgery. Clin J Oncol Nurs. 1999;3:99-106.

3. Segal O, Bellemans J, Van Gerven E, Deneckere S, Panella M, Sermeus W, Vanhaecht K. Important variations in the content of care pathway documents for total knee arthroplasty may lead to quality and patient safety problems. J Eval Clin Pract. 2013;19:11-5.

4. Every NR, Hochman J, Becker R, Kopecky S, Cannon CP. Critical pathways: a review. Committee on Acute Cardiac Care, Council on Clinical Cardiology, American Heart Association. Circulation. 2000;101:461-5.

5. Pearson SD, Goulart-Fisher D, Lee TH. Critical pathways as a strategy for improving care: problems and potential. Ann Intern Med. 1995;123:941-8.

6. Ayalon O, Liu S, Flics S, Cahill J, Juliano K, Cornell CN. A multimodal clinical pathway can reduce length of stay after total knee arthroplasty. HSS J. 2011;7:9-15.

7. Husni ME, Losina E, Fossel AH, Solomon DH, Mahomed NN, Katz JN. Decreasing medical complications for total knee arthroplasty: effect of critical pathways on outcomes. 
BMC Musculoskelet Disord. 2010;11:160.

8. Kim S, Losina E, Solomon DH, Wright J, Katz JN. Effectiveness of clinical pathways for total knee and total hip arthroplasty: literature review. J Arthroplasty. 2003;18:69-74.

9. Kirschner S, Lützner J, Meier V, Gunther KP, Krummenauer F. Clinical pathway for total knee arthroplasty (EGON). II: the impact of enhanced patient information. Orthopade. 2010;39:860-5.

10. Malviya A, Martin K, Harper I, Muller SD, Emmerson KP, Partington PF, Reed MR. Enhanced recovery program for hip and knee replacement reduces death rate. Acta Orthop. 2011;82:577-81.

11. Pearson S, Moraw I, Maddern GJ. Clinical pathway management of total knee arthroplasty: a retrospective comparative study. Aust N Z J Surg. 2000;70:351-4.

12. Vanhaecht K, Bellemans J, De Witte K, Diya L, Lesaffre E, Sermeus W. Does the organization of care processes affect outcomes in patients undergoing total joint replacement? J Eval Clin Pract. 2010;16:121-8.

13. Xu GG, Sathappan SS, Jaipaul J, Chan SP, Lai CH. A review of clinical pathway data of 1,663 total knee arthroplasties in a tertiary institution in Singapore. Ann Acad Med Singapore. 2008;37:924-8.

14. Barbieri A, Vanhaecht K, Van Herck P, Sermeus W, Faggiano F, Marchisio S, Panella M. Effects of clinical pathways in the joint replacement: a meta-analysis. BMC Med. 2009;7:32.

15. Berger RA, Kusuma SK, Sanders SA, Thill ES, Sporer SM. The feasibility and perioperative complications of outpatient knee arthroplasty. Clin Orthop Relat Res. 2009;467:1443-9.

16. Pearson SD, Kleefield SF, Soukop JR, Cook EF, Lee TH. Critical pathways intervention to reduce length of hospital stay. Am J Med. 2001;110:175-80.

17. Santillan A, Govan L, Zahurak ML, Diaz-Montes TP, Giuntoli RL 2nd, Bristow RE. Feasibility and economic impact of a clinical pathway for pap test utilization in Gynecologic Oncology practice. Gynecol Oncol. 2008;109:388-93.

18. Brunenberg DE, van Steyn MJ, Sluimer JC, Bekebrede LL, Bulstra SK, Joore MA. Joint recovery programme versus usual care: an economic evaluation of a clinical pathway for joint replacement surgery. Med Care. 2005;43:1018-26.

19. Lin YK, Su JY, Lin GT, Tien YC, Chien SS, Lin CJ, Cheng YM, Lin SY. Impact of a clinical pathway for total knee arthroplasty. Kaohsiung J Med Sci. 2002;18:134-40.

20. Healy WL, Iorio R, Ko J, Appleby D, Lemos DW. Impact of cost reduction programs on short-term patient outcome and hospital cost of total knee arthroplasty. J Bone Joint Surg Am. 2002;84:348-53.

21. Scranton PE Jr. The cost effectiveness of streamlined care pathways and product standardization in total knee arthroplasty. J Arthroplasty. 1999;14:182-6.

22. Wammack L, Mabrey JD. Outcomes assessment of total hip and total knee arthroplasty: critical pathways, variance analysis, and continuous quality improvement. Clin Nurse Spec. 1998;12:122-9.

23. Macario A, Horne M, Goodman S, Vitez T, Dexter F, Heinen $\mathrm{R}$, Brown $\mathrm{B}$. The effect of a perioperative clinical pathway for knee replacement surgery on hospital costs. Anesth Analg. 1998;86:978-84.

24. Kishimoto T, Imamura H, Kawabata R, Kimura Y, Fukunaga M, Ohzato H. Feasibility and outcome of S-1 adjuvant chemotherapy for patients with gastric cancer treated based on the liaison-clinical pathway. Gan To Kagaku Ryoho. 2013;40: 489-92.

25. den Hertog A, Gliesche K, Timm J, Mühlbauer B, Zebrowski S. Pathway-controlled fast-track rehabilitation after total knee arthroplasty: a randomized prospective clinical study evaluating the recovery pattern, drug consumption, and length of stay. Arch Orthop Trauma Surg. 2012;132:1153-63.

26. Koh IJ, Chang CB, Lee JH, Jeon YT, Kim TK. Preemptive low-dose dexamethasone reduces postoperative emesis and pain after TKA: a randomized controlled study. Clin Orthop Relat Res. 2013;471:3010-20.

27. Kim TK, Chang CB, Kang YG, Seo ES, Lee JH, Yun JH, Lee SH. Clinical value of tranexamic acid in unilateral and simultaneous bilateral TKAs under a contemporary bloodsaving protocol: a randomized controlled trial. Knee Surg Sports Traumatol Arthrosc. 2014;22:1870-8.

28. Koh IJ, Kim TK, Chang CB, Cho HJ, In Y. Trends in use of total knee arthroplasty in Korea from 2001 to 2010. Clin Orthop Relat Res. 2013;471:1441-50.

29. Renkawitz T, Rieder T, Handel M, Koller M, Drescher J, Bonnlaender G, Grifka J. Comparison of two accelerated clinical pathways: after total knee replacement how fast can we really go? Clin Rehabil. 2010;24:230-9.

30. Pennington JM, Jones DP, McIntyre S. Clinical pathways in total knee arthroplasty: a New Zealand experience. J Orthop Surg (Hong Kong). 2003;11:166-73. 
Appendix

This questionnaire was designed for the health care providers who cared for patients who underwent total knee arthroplasty with application of the clinical pathway (CP) to research the benefits of the $\mathrm{CP}$ and complement the $\mathrm{CP}$. The data collected through this survey will be used to improve the CP. Please answer all questions as sincerely as possible.

- Questions about the Responders

A1. Jobs and work period

$\square$ Resident
$\square$ 1st year
$\square$ 2nd year
3rd year
4th year

$\square$ Nurse

How long have you worked as a nurse?
$\square$ Less than 1 year
$\square 1-3$ years
3-5 years
$\square$ More than 5 years

- Items below are the known benefits of a CP. What do you think of each item described below? How much are these associated with the currently used $\mathrm{CP}$ ?

B1. The CP improves quality of medical service.
5. Strongly agree
$\square$ 4. Agree
3. Neutral
2. Disagree
1. Strongly disagree

B2. The CP decreased the costs of medical care.
5. Strongly agree
$\square$ 4. Agree
3. Neutral
2. Disagree
1. Strongly disagree

B3. The $\mathrm{CP}$ reduced the workload i.e., decreased time for entering the order.
$\square$ 5. Strongly agree
$\square$ 4. Agree
$\square$ 3. Neutral
2. Disagree
1. Strongly disagree

B4. The CP facilitates transferring a duty over to another provider.
$\square$ 5. Strongly agree
$\square$ 4. Agree
$\square$ 3. Neutral
$\square$ 2. Disagree
1. Strongly disagree

B5. The CP reduced medical errors, i.e., reduced faulty orders.
5. Strongly agree
$\square$ 4. Agree
3. Neutral
$\square$ 2. Disagree
1. Strongly disagree

B6. The $\mathrm{CP}$ has educational benefits, i.e. understanding the standardized process for TKR patient care.
5. Strongly agree
$\square$ 4. Agree
3. Neutral
$\square$ 2. Disagree
1. Strongly disagree

B7. The CP improved communication with the patients/guardians.
5. Strongly agree
$\square$ 4. Agree
3. Neutral
2. Disagree
1. Strongly disagree

B8. The CP improved communication between medical staff.
5. Strongly agree
$\square$ 4. Agree
3. Neutral
2. Disagree
1. Strongly disagree

B9. The CP reduced length of stay.
$\square$ 5. Strongly agree
4. Agree
3. Neutral
$\square$ 2. Disagree
1. Strongly disagree

- Items below are the known weaknesses of CP. What do you think of each item described below?

$\mathrm{C} 1$. The $\mathrm{CP}$ inhibits coping with the diverse situations of individual patients
$\square$ 5. Strongly agree
$\square$ 4. Agree
3. Neutral
2. Disagree
1. Strongly disagree

$\mathrm{C} 2$. The $\mathrm{CP}$ inhibits creative thinking as a trainee.
$\square$ 5. Strongly agree
$\square$ 4. Agree
3. Neutral
2. Disagree
1. Strongly disagree

C3. The CP inhibits additional insertion/performance of an order.
5. Strongly agree
$\square$ 4. Agree
3. Neutral
2. Disagree
1. Strongly disagree

$\mathrm{C} 4$. The $\mathrm{CP}$ has a higher risk of malpractice when the compliance of the patient with the $\mathrm{CP}$ is low or a complication occurs.
$\square$ 5. Strongly agree
$\square$ 4. Agree
$\square$ 3. Neutral
$\square$ 2. Disagree
1. Strongly disagree

- Items below are description of your general feelings about the CP. What is your feeling?

D1. The currently used CP improves general medical process.
$\square$ 5. Strongly agree
$\square$ 4. Agree
3. Neutral
$\square$ 2. Disagree
1. Strongly disagree

D2. If you had the right to choose whether to use the $\mathrm{CP}$, you would choose to use the $\mathrm{CP}$.
$\square$ 5. Strongly agree
$\square$ 4. Agree
3. Neutral
2. Disagree
1. Strongly disagree

D3. What is your satisfaction level with the CP? (0: very dissatisfied, 10: very satisfied)

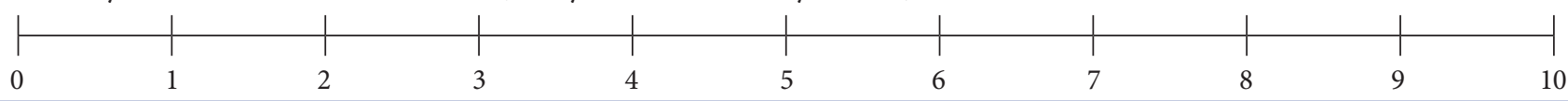

